\title{
The use of energy-saving technologies in the overhaul and reconstruction of buildings
}

\author{
Varvara Dikareva ${ }^{1, *}$, Miron Karpovich ${ }^{2}$, and Zinaida Petrikova ${ }^{2}$ \\ ${ }^{1}$ Moscow State University of Civil Engineering, 26, Yaroslavskoe sh., Moscow, 129337, Russia \\ ${ }^{2}$ Voronezh State Technical University, 14, Moscow Avenue, Voronezh, 394026, Russia
}

\begin{abstract}
The purpose of this paper is to develop mechanisms to improve the efficiency of reconstruction and overhaul of buildings based on the use of energy-saving technologies. As a result of the study, ways have been developed to increase the efficiency of reconstruction and overhaul based on energy conservation, including legal regulation, institutional and organizational development, technical and information support for energy conservation measures as part of the overhaul and reconstruction of residential and public buildings. A method has been formed for the selection and assessment of the efficiency of energy-saving technological solutions, taking into account both technical and economic criteria, which allows assessing the long-term sustainability of investment projects for the implementation of energy-saving measures and determining the necessary degree of government participation in investment.
\end{abstract}

\section{Introduction}

The study of the essence of the energy saving potential of buildings, as well as the study of regulatory documents, economic literature and the existing practice of energy saving in the Russian Federation, showed that the definitions used for the concept of "energy saving potential" do not fully take into account the specifics of operating public and residential buildings. In most buildings, energy efficiency is achieved by eliminating the use of such life support systems as ventilation, which leads to a violation of sanitary requirements established for this type of buildings and a decrease in the comfort of staying in them [1].

In this regard, specifying the concept of "Energy saving potential" for the end consumer of fuel and energy resources - an organization operating a public building or the owner of a residential building, we suggest defining the energy saving potential as the number of energy resources that can be saved as a result of the implementation of technically feasible and economically viable measures aimed at their effective use, subject to the observance of sanitary and other mandatory norms established for a particular type of buildings and structures [2].

\section{Materials and Methods}

\footnotetext{
${ }^{*}$ Corresponding author: dikareva-va@rambler.ru
} 
The effectiveness of overhaul and reconstruction of buildings is directly related to the problem of energy conservation and energy efficiency. Calculations showed that the use of modern technologies for thermal insulation of building envelopes during overhaul can save up to $40 \%$ of heating costs. Improving the efficiency of overhauls and reconstruction of buildings based on energy conservation is impossible without state support at all levels. Based on an analysis of Russian and international experience, current state policy and legal regulation, we have developed five directions for improving the efficiency of overhauls and reconstruction of residential and public buildings based on energy conservation [3].

A set of measures taken by government and municipal authorities in the framework of these areas, aimed at ensuring close coordination of the overhaul planning of residential and public buildings with the planning of energy saving and energy efficiency measures is presented in Fig. 1 on the next page.

Energy-saving measures are usually classified according to two main criteria [4]:

1)In terms of capital intensity and terms of implementation:

- low cost (quick return measures);

- medium cost (base);

- high-cost (long-term),

2) By type:

- technical;

- economical;

- organizational;

- informational.

We detailed the existing classification and supplemented it with two additional classification features:

- attractiveness of investment;

- place in the production cycle.

On the basis of attractiveness, we distinguished two types of investments in energysaving measures:

1) Investments attractive to the end consumer of fuel and energy resources

2) Investments attractive to the government.

Investments should be considered attractive to the government if the cost of saving a unit of energy (for example, $1 \mathrm{kWh}$ ) is less than the cost of building a new generating capacity (for example, $1 \mathrm{~kW}$ ) or than the amount of lost profit for the country from exporting a unit of fuel - depending on which of these values is greater.

Investments become attractive to the consumer of fuel and energy resources if the cost of saving a unit of energy (for example, $1 \mathrm{kWh}$ ) is less than the cost of acquiring an additional unit of energy. 


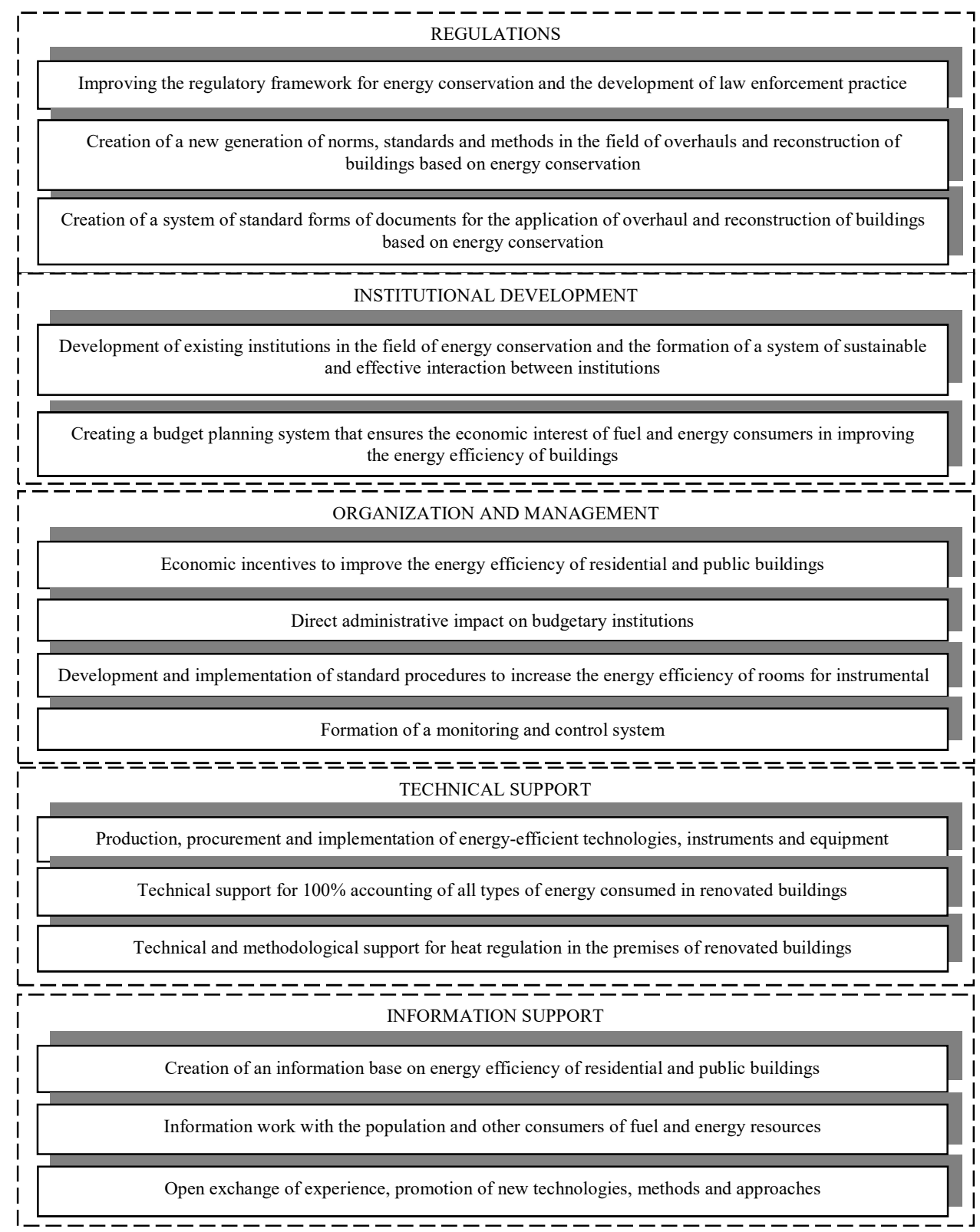

Fig. 1. The main ways of increasing the efficiency of overhauls and reconstruction of residential and public buildings based on energy conservation.

According to their place in the operational cycle, we divided energy-saving measures into those that can be carried out as part of daily operation and maintenance, and those that can only be carried out as part of an overhaul, modernization or reconstruction of the building. The latter are always referred to as long-term categories [5, 6]. The full classification of energy-saving measures for residential and public buildings proposed by the author is presented in Fig. 2. 


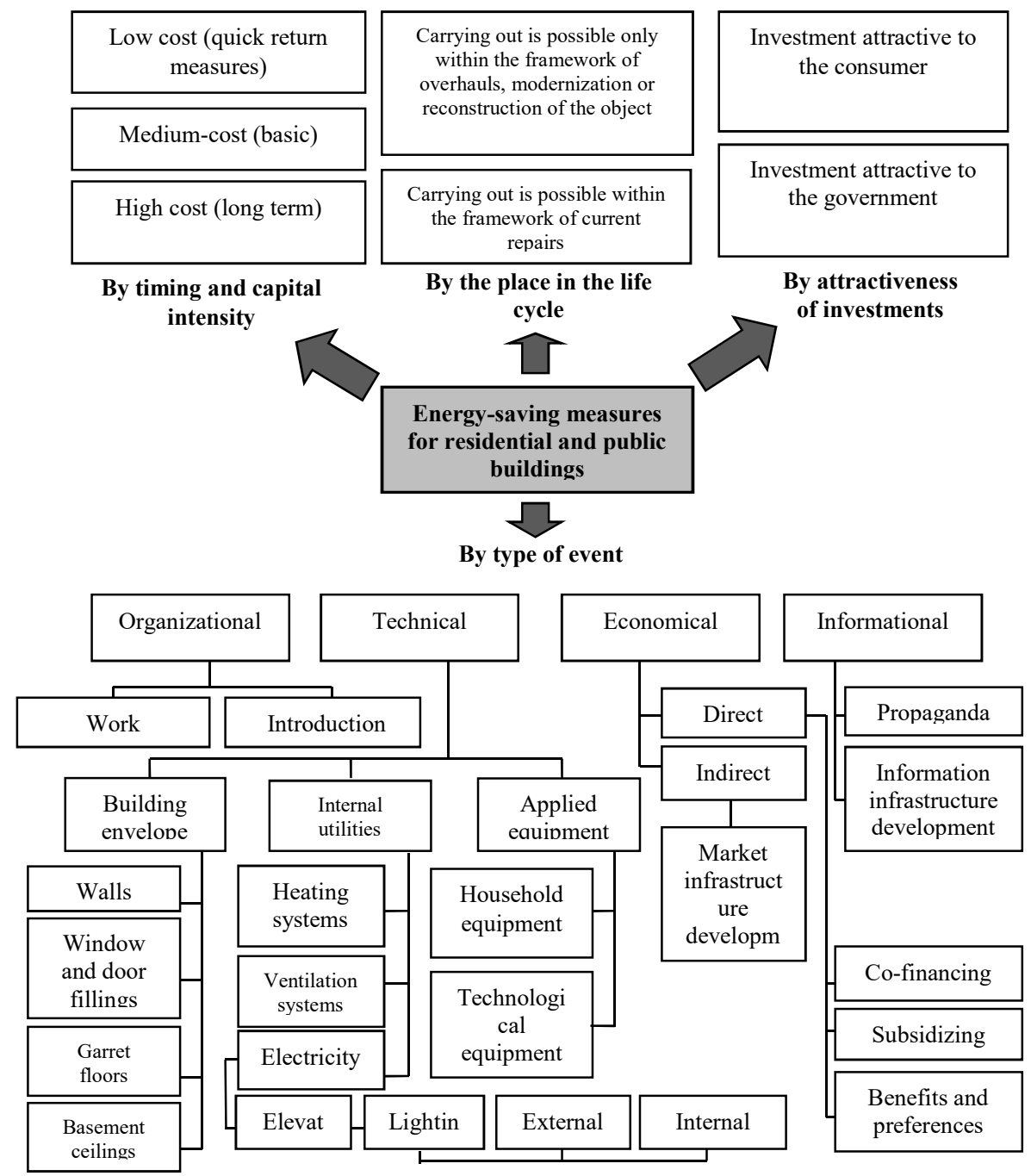

Fig. 2. Classification of energy-saving measures.

An assessment of the energy saving potential of the end consumer of fuel and energy resources is carried out in the course of an energy audit, as a result of which measures are being developed to save energy and increase the energy efficiency of the consumer of fuel and energy resources, which should form the basis of the energy efficiency program developed and implemented in conjunction with the implementation of plans and programs of current repairs and overhauls of operated buildings [7,8].

\section{Results}

The general algorithm for assessing the energy saving potential of a building and its implementation due to overhaul is presented in Fig. 3. 


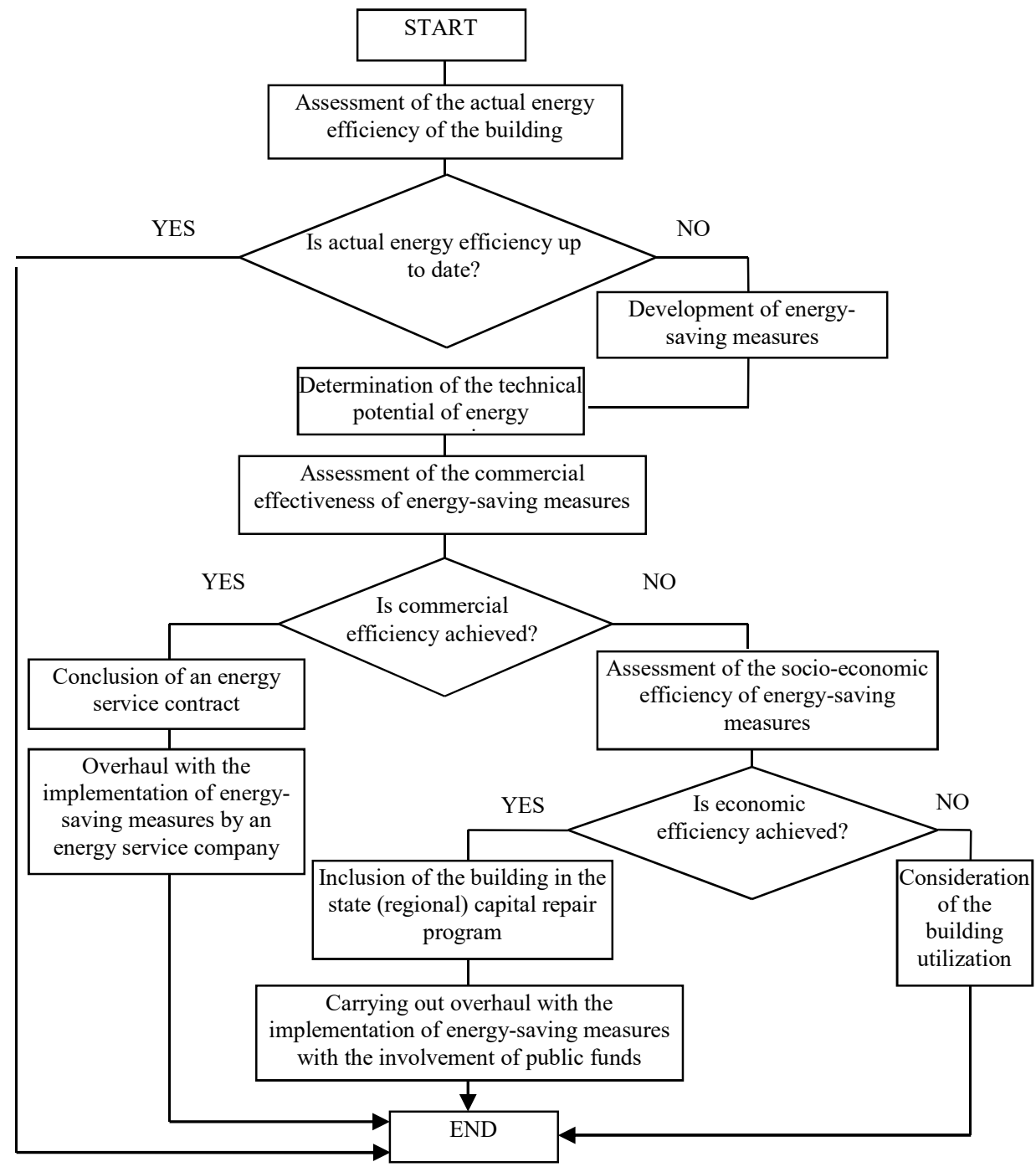

Fig. 3. Algorithm for assessing the energy saving potential of a building and its implementation due to overhaul.

We propose to determine the efficiency of overhaul and reconstruction programs for residential and public buildings on the basis of energy saving by summing up the indicators of economic effect (NPV - net present value) obtained as a result of increasing the energy efficiency of each renovated building. The redacting indicator is the discounted payback period, which should not exceed the interval between overhauls equal to 25-30 years. Efficiency assessment is carried out separately for investments attractive to the government and investments attractive to end consumers as shown in formulas 1 and $2[9,10]$.

$$
N P V_{j}^{g o v}=\sum_{t=0}^{T} N V_{j t} \cdot a_{t}^{g o v}=\sum_{t=0}^{T}\left(R_{j t}-C_{j t}\right) \cdot a_{t}^{g o v}
$$




$$
N P V_{j}^{c o m m}=\sum_{t=0}^{T} N V_{j t} \cdot a_{t}^{c o m m}=\sum_{t=0}^{T}\left(R_{j t}-C_{j t}\right) \cdot a_{t}^{c o m m}
$$

where $N V_{j t}$ - net income generated by the $j$-th project at the $t$-th step, rub;

$R_{j t}$ - the result of the $j$-th project at the $t$-th step, rub.;

$C_{j t}$-investment and current operating costs for the $j$-th project at the $t$-th step, rub.;

$a_{t}^{\text {gov }}, a_{t}^{\text {comm }}$ - discount factors for the government and end consumers at the $t$-th step, respectively;

$j=1,2, \ldots, J$; where $J$ - the set of projects for the overhaul or reconstruction of residential or public buildings;

$T$ - settlement period (time horizon), years.

\section{Discussions}

As a result of the study, the classification of energy-saving measures in relation to residential and public buildings has been refined and supplemented, which is based on four distinctive features: a place in the production cycle, subject of modernization, term and capital intensity; investment efficiency.

\section{Conclusion}

The developed algorithm makes it possible to determine and realize the energy-saving potential of buildings as part of reconstruction and overhaul, providing for the selection of sources and financing schemes, depending on the results of assessing the socio-economic and commercial effectiveness of the planned energy-saving measures

\section{References}

1. S. Barkalov, P. Kurochka, T. Nasonova, MATEC Web of Conferences conference proceedings, 01124 (2018)

2. E. Avdeeva, T. Averina, L. Kochetova, E3S Web of Conferences, 03013 (2018)

3. T. Averina, E. Avdeeva, O. Perevalova, MATEC Web of Conferences conference proceedings, 01121 (2018)

4. V.V. Breer, D.A. Novikov, A.D. Rogatkina, Crowd Management: Mathematical models of Threshold Collective Behavior (LENAND, Moscow, 2016)

5. V.V. Ivanov, G.G. Malinetsky, International scientific and analytical journal "Strategic Priorities" 3(15), 54-95 (2017)

6. V.N. Burkov, I.V. Burkova, S.A. Barkalov, FES: Finance. Economy 15(4), 5-10 (2018)

7. S.A. Barkalov, Information Technology in Economics and Management: Studies Manual (Scientific book, Voronezh, 2009)

8. V. Burkov, A. Shchepkin, V. Irikov, V. Kondratiev, Studies in Systems, Decision and Control 181, 29-38 (2019) 
9. S.A. Barkalov, O. Kravec, P.N. Kurochka, T.V. Nasonova, A.I. Polovinkina, International Journal of Pure and Applied Mathematics 117(4), 83-87 (2017)

10. E.V. Orlova, Proceedings of the Mathematical Modeling Session at the International Conference Information Technology and Nanotechnology (MM-ITNT 2017) 1904, 1-6 (2017) 